\title{
Nuclear Factor-Kappa B and Alzheimer Disease, Unifying Genetic and Environmental Risk Factors from Cell to Humans
}

\author{
Simon Vann Jones ${ }^{1}$ and Ilias Kounatidis ${ }^{2 *}$ \\ ${ }^{1}$ Department of Psychiatry, Warneford Hospital, University of Oxford, Oxford, United Kingdom, ${ }^{2}$ Laboratory of Cell Biology, \\ Development and Genetics, Department of Biochemistry, University of Oxford, Oxford, United Kingdom
}

OPEN ACCESS

Edited by:

Masaaki Murakami,

Hokkaido University, Japan

Reviewed by:

Ché Serguera,

Institut National de la Santé et de la

Recherche Médicale, France Mireia Guerau-de-Arellano,

The Ohio State University,

United States

${ }^{*}$ Correspondence: llias Kounatidis

ilias.kounatidis@bioch.ox.ac.uk

Specialty section: This article was submitted to Multiple Sclerosis and Neuroimmunology, a section of the journal

Frontiers in Immunology

Received: 31 August 2017 Accepted: 30 November 2017 Published: 11 December 2017

Citation:

Jones SV and Kounatidis I (2017) Nuclear Factor-Kappa B and

Alzheimer Disease, Unifying

Genetic and Environmental Risk

Factors from Cell to Humans.

Front. Immunol. 8:1805. doi: 10.3389/fimmu.2017.01805
Alzheimer's disease (AD) is the most common form of dementia, an eversible, progressive disease that causes problems with memory, thinking, language, planning, and behavior. There are a number of risk factors associated with developing AD but the exact cause remains unknown. The predominant theory is that excessive build-up of amyloid protein leads to cell death, brain atrophy, and cognitive and functional decline. However, the amyloid hypothesis has not led to a single successful treatment. The recent failure of Solanezumab, a monoclonal antibody to amyloid, in a large phase III trial was emblematic of the repeated failure of anti-amyloid therapeutics. New disease targets are urgently needed. The innate immune system is increasingly being implicated in the pathology of number of chronic diseases. This focused review will summarize the role of transcription factor nuclear factor-kappa $B(N F-\kappa B)$, a key regulator of innate immunity, in the major genetic and environmental risk factors in cellular, invertebrate and vertebrate models of AD. The paper will also explore the relationship between $\mathrm{NF}-\mathrm{kB}$ and emerging environmental risk factors in an attempt to assess the potential for this transcription factor to be targeted for disease prevention.

\section{Keywords: nuclear factor-kappa B, Alzheimer, dementia, cell lines, invertebrate models, rodents, humans}

\section{INTRODUCTION}

The global burden of dementia is devastating, with an estimated 35 million people affected and the annual cost estimated to exceed $\$ 1$ trillion by $2018(1,2)$. Despite greater knowledge of the pathogenic sequelae of disease, repeated failure in drug trials has led to a switch in emphasis from disease treatment to disease prevention (3-5). Alzheimer's disease (AD) is the most common dementia subtype yet no single theory has been able to account for the multiple risk factors leading to the pathological and clinical features (3). The deposition of excess extracellular beta amyloid $(\mathrm{A} \beta)$ protein and subsequent taupathy has long been felt to be a cause of the disease overshadowing alternative hypotheses including microglial dysfunction, vascular disease, mitochondrial insufficiency, and metabolic disease.

However, the recent failure of another promising anti-amyloid treatment in large phase III trials has dealt a significant blow to the credibility of the amyloid hypothesis (6). The pathognomonic role of $A \beta$ is now also being questioned with the discovery that $A \beta$ acts as an antimicrobial peptide (AMP) in cell lines, nematode, and rodent models. $\mathrm{A} \beta$ production following exposure to neurotoxic fungi and bacteria provided significant neuroprotection (7). Amyloid over-production may therefore 
be a downstream product of immune dysregulation rather than a disease process in itself. In support of this, several genes are involved in innate immunity are associated with an increase in AD (8) (see Table 1). More work is clearly needed to explore the interaction between amyloid and the innate immune system.

Aging is the most significant risk factor for developing $\mathrm{AD}$ and recent findings have shown tissue specific brain inflammation, mediated by NF- $\mathrm{BB}$ is associated with aging (12-15). Hypothalamic NF- $\mathrm{B}$ levels are negligible in young mice and Drosophila. Significant activation begins in middle age. The resulting downstream increase in AMPs leads to increased local microglial activity, subsequent decline in gonadotrophins and aging $(12,14)$. Interestingly, hypothalamic inflammation is relatively higher when compared to neurons and glial cells in other vulnerable brain regions such as the hippocampus (12). In support of this hypothalamic-specific regulation of aging, drugs known to extend lifespan in mice reduce hypothalamic inflammation but have little anti-inflammatory effect on hippocampal neurons (14).

Known inducers of NF- $\mathrm{KB}$ activity are highly variable and include reactive oxygen species (ROS), interleukin 1-beta (IL$1 \beta$ ), tumor necrosis factor alpha (TNF- $\alpha$ ), bacterial lipopolysaccharides (LPS), isoproterenol, and ionizing radiation $(16,17)$. In addition to stimuli that activate NF- $\kappa \mathrm{B}$ in other tissues, NF- $\kappa \mathrm{B}$ in the nervous system can be activated by growth factors and synaptic transmission such as glutamate (18). These activators of NF- $\kappa \mathrm{B}$ in the nervous system all converge upon the inhibitor of kinase kinase (IKK) complex (Figure 1).

Nuclear factor-kappa B transcription factors include a collection of proteins with functions conserved from the fruit fly Drosophila melanogaster to rodents and to humans (Figures 1 and 2). They are present in all human and most animal cells and regulate the expression of more than 400 genes, including a multitude of inflammatory mediators associated with a variety of chronic inflammatory diseases including cancer, diabetes, and $\operatorname{AD}(19,20)$. Lately, Rel/NF- $\mathrm{B}$ homologs have also been found to occur even in organisms as simple as Cnidarians (e.g., sea anemones and corals), Porifera (sponges), and the single-celled eukaryote Capsaspora owczarzaki, but are notably absent in yeast and the nematode Caenorhabditis elegans (21). Activated NF- $\kappa \mathrm{B}$ regulates the expression of specific genes, including isoforms of SET, directly implicated in the pathogenesis of AD (22). Conversely, expression of the mammalian family of Sirtuin deacetylases, known to attenuate the effects of aging, down regulates NF-kB $(23,24)$.
Studies of aging populations have enabled the identification of a number of genetic and environmental risk factors that appear to influence susceptibility to developing $\operatorname{AD}(25,26)$. This paper will review the interaction between these risk factors and $\mathrm{NF}-\kappa \mathrm{B}$, first looking at the major known genetic risk factors in cell, invertebrate, and vertebrate models. It will then focus on the major known environmental risk factors in these models before reviewing emerging environmental risk factors. Finally, the paper will review protective mechanisms across various experimental models and whether their association with NF- $\mathrm{kB}$.

The repeated failure of disease modifying trials in $\mathrm{AD}$ demands that new treatment targets are urgently identified. The recent findings that implicate the innate immune system in $\mathrm{AD}$ provides an opportunity to review the evidence for NF- $\mathrm{\kappa B}$ as a key immune system regulator in the prodromal stage in the hope of identifying a target for treatment and prevention.

\section{GENETICS}

\section{Neuronal Cell Lines/Human Autopsy Studies}

Overexpression of the amyloid precursor protein (APP) gene is associated with familial aggregation of late onset $\mathrm{AD}$ and dramatically increases susceptibility to early AD in Down's syndrome. APP is cleaved by the beta-secreatase BACE1 into amyloid monomers that form oligomers that eventually become plaques in the brain and vasculature. Both BACE1 and NF- $\mathrm{KB}$ are increased in the brains of $\mathrm{AD}$ patients, with NF- $\mathrm{\kappa B}$ directly upregulating BACE1 and the APP gene $(27,28)$. Medications such as minocycline, that inhibit NF- $\kappa \mathrm{B}$ but not BACE1 or APP, reverse this process $(28,29)$.

The 4 variant of the APOE gene, which codes for a cholesterol transporting protein, is the largest, single gene risk factor for AD (30). In APOE e4-positive Schwann cell lines, when compared to APOE e3-expressing cells, excess production of IL6, IL10, and nitrous oxide results from a failure to inhibit NF- $\kappa B$ (31). These findings are replicated in neural cells and fibroblasts from $\mathrm{AD}$ patients where APOE e4 acts as a transcription factor responsible for regulating NF- $\mathrm{\kappa B}$ expression (32). Curiously, cells from the somatosensory cortex of $\mathrm{AD}$ patients, an area of the brain that is resistant to disease, display upregulation of NF- $\kappa \mathrm{B}$ (33). However, this may reflect the earliest inflammatory hallmark of disease as previous autopsy studies have shown increased NF- $\mathrm{KB}$ activation in evolving $A \beta$ deposits with a reduction in areas surrounding more mature plaques $(19,33)$.

TABLE 1 | Emerging genetic risk factors for Alzheimer's disease (AD) and their associated with nuclear factor-kappa B (NF-kB) and amyloid (8).

\begin{tabular}{|c|c|c|c|c|}
\hline $\begin{array}{l}\text { Gene implicated } \\
\text { in late onset } A D\end{array}$ & Function & Increased risk of AD & Interaction with NF-кB & Interaction with amyloid \\
\hline TREM2 & Immunity & $\begin{array}{l}\text { Reduced expression increases } \\
\text { risk: slight-medium }\end{array}$ & NF-кB suppresses hippocampal TREM2 expression (9) & $\begin{array}{l}\text { TREM2 required for microglial } \\
\text { amyloid clearance (9) }\end{array}$ \\
\hline CD33 & Immunity & Mild & CD33 activates NF-кB in myeloid cells & $\begin{array}{l}\text { CD33 inhibits microglial } A \beta \\
\text { uptake and clearance }(10)\end{array}$ \\
\hline CR1 & Immunity & Mild-medium & Microglial CR1 activation associated with increase in NF-kB (11) & Uncertain (11) \\
\hline INPP5D & Immunity & Mild & Negative regulator of NF-кB expression (12) & Uncertain \\
\hline
\end{tabular}



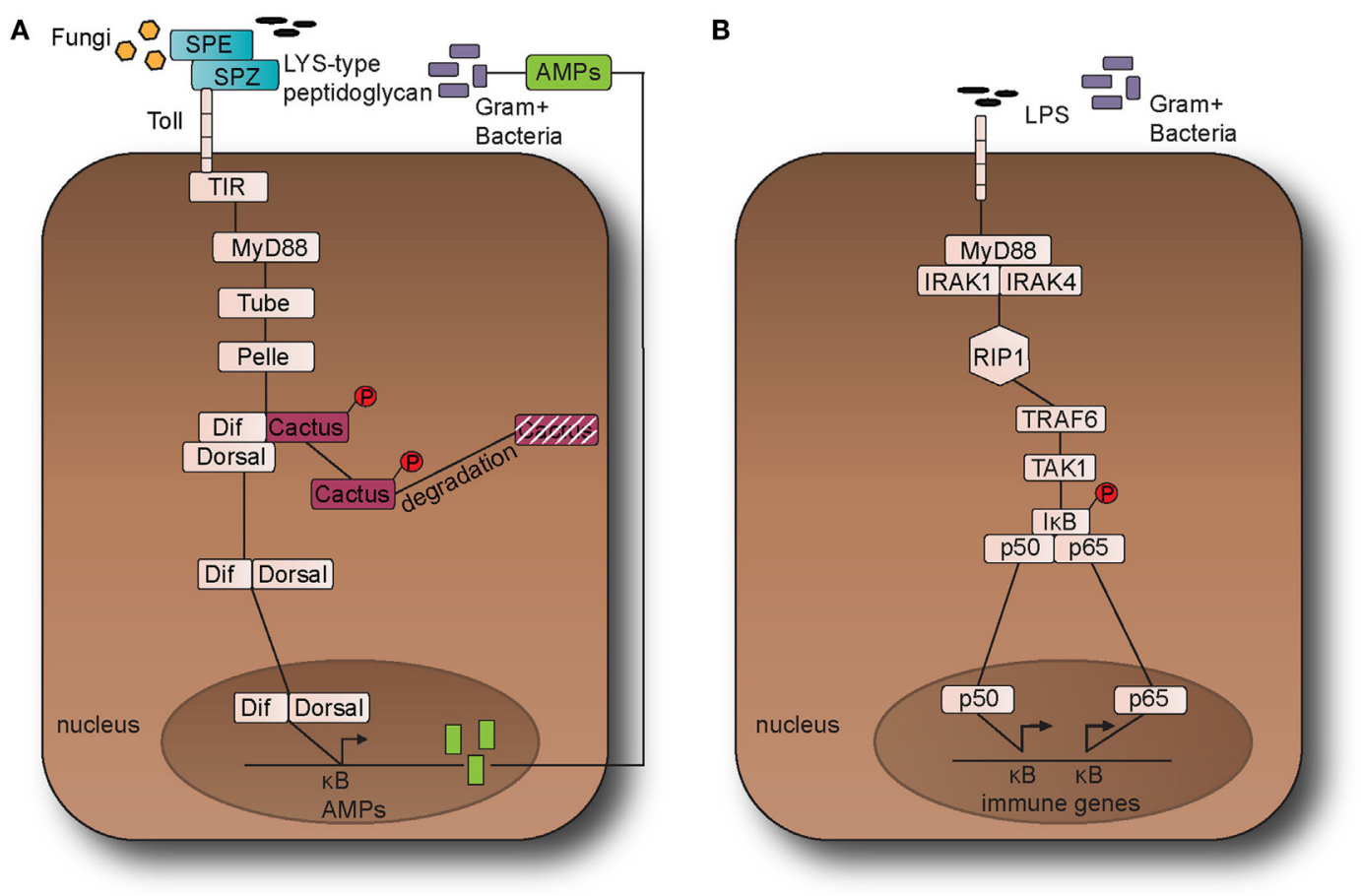

FIGURE 1 | The Toll pathway in fruit fly and the Toll-like receptor (TLR) 4 pathway in the mouse. (A) The Toll pathway in Drosophila melanogaster detects Grampositive bacteria and fungi is activated through an endogenous ligand, namely Nerve Growth Factor-related cytokine Spaetzle (SPZ) which is processed by Spaetzleprocessing enzyme (SPE). Toll receptor activation results in the recruitment of the adaptor proteins namely myeloid differentiation primary response 88 (dMyD88), Tube, and Pelle, which promotes signaling to Cactus and its ankyrin-repeat domains. Cactus is bound to the nuclear factor-kappa B (NF- $\mathrm{B}$ ) transcription factors dorsal-related immunity factor (DIF) and Dorsal and following activation of the pathway, it is phosphorylated and degraded. The above signaling events result in the nuclear translocation of DIF or Dorsal that stimulate the transcriptional upregulation of antimicrobial peptide (AMP) genes, such as Drosomycin. (B). TLR4 receptor in M. musculus detects lipopolysaccharides (LPS) from Gram-negative bacteria. Myeloid differentiation primary response 88 (MyD88) is recruited with Interleukin-1 receptor-associated kinases 1 and 4 (IRAK1, IRAK4), receptor-interacting protein 1 (RIP1), and tumor necrosis factor (TNF) receptor-associated factor 6 (TRAF6). TRAF6 is self-ubiquitinated in order to recruit transforming growth factor beta (TGF- $\beta$ ) activated kinase 1 (TAK1) and TAK1-associated binding proteins 1 and 2

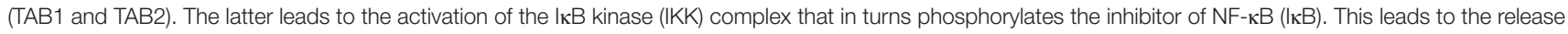
of NF-kB that translocates to the nucleus and initiates the transcriptional induction of inflammatory and immune response related genes. This leads to the translocation of the NF-kB transcription factors p50 and p65 to the nucleus, which in turns initiates the transcriptional induction of inflammatory and immune response related genes.

\section{Invertebrate Models}

A genetic screen for dominant suppressors and enhancers in a Drosophila model of $\mathrm{A} \beta$-driven neurodegeneration revealed that Toll gene (receptor of Drosophila toll pathway) and key downstream components (dif, pelle, cactus), play a central role in mediating the neuropathological activities (34). Conversely, genetic overexpression results in accelerated deterioration of the phenotype suggesting that NF- $\mathrm{BB}$ significantly enhances the pathological potential of $A \beta$ (35).

Genetic suppression of the immune deficiency (IMD) NF- $\kappa B$ pathway in glial cells in a Drosophila model of early onset neurodegeneration dramatically rescues brain pathology, reduced activity, and short lifespan (13). Genetic overexpression of NF- $\kappa \mathrm{B}$ pathways at neuronal or glial tissue level leads to phenotypes resembling $\mathrm{AD}$ models with locomotor disability, accelerated neurodegeneration, and premature mortality (13).

\section{Vertebrate Models}

Age is the biggest risk factor for dementia and systemic inflammation increases as animal's age, a process known as inflammaging (36). Microglia priming in mice induces a highly conserved transcriptional signature with aging characterized by NF- $\kappa \mathrm{B}$ expression and neuronal death (37). In rats, NF- $\kappa \mathrm{B}$ expression increases in normal aging leading to production of neurodegenerative pro-inflammatory enzymes COX-2 and iNOS (38). These changes are reversed by suppression of brain NF- $\mathrm{B}$ activation using the anti-inflammatory Lactobacillus pentosus var. plantarum $\mathrm{C} 29$, restoring brain-derived neurotrophic factor (BDNF) levels and memory (39). In mice, the observed positive correlation between NF- $\mathrm{KB}$ activity and neuronal apoptosis suggests a role of NF- $\mathrm{\kappa B}$ in hippocampal neuroapoptosis (40). Supporting this, NF- $\kappa \mathrm{B}$ induces pro-apoptotic increases in TNF and iNOS in the hippocampus of rats exposed to neurotoxin (41).

Inactivating specific Sirtuin anti-aging genes in mice results in chronic NF- $\kappa \mathrm{B}$ overexpression leading to accelerated aging and dramatically reduced lifespan (23). In Sirtuin replete models, overexpression via biofeedback dysregulation results in premature aging through chronic production of excessive ROS, leading to telomere dysfunction, cellular senescence, and premature death (42). Age-related NF- $\kappa \mathrm{B}$ activation feeds into a positive 

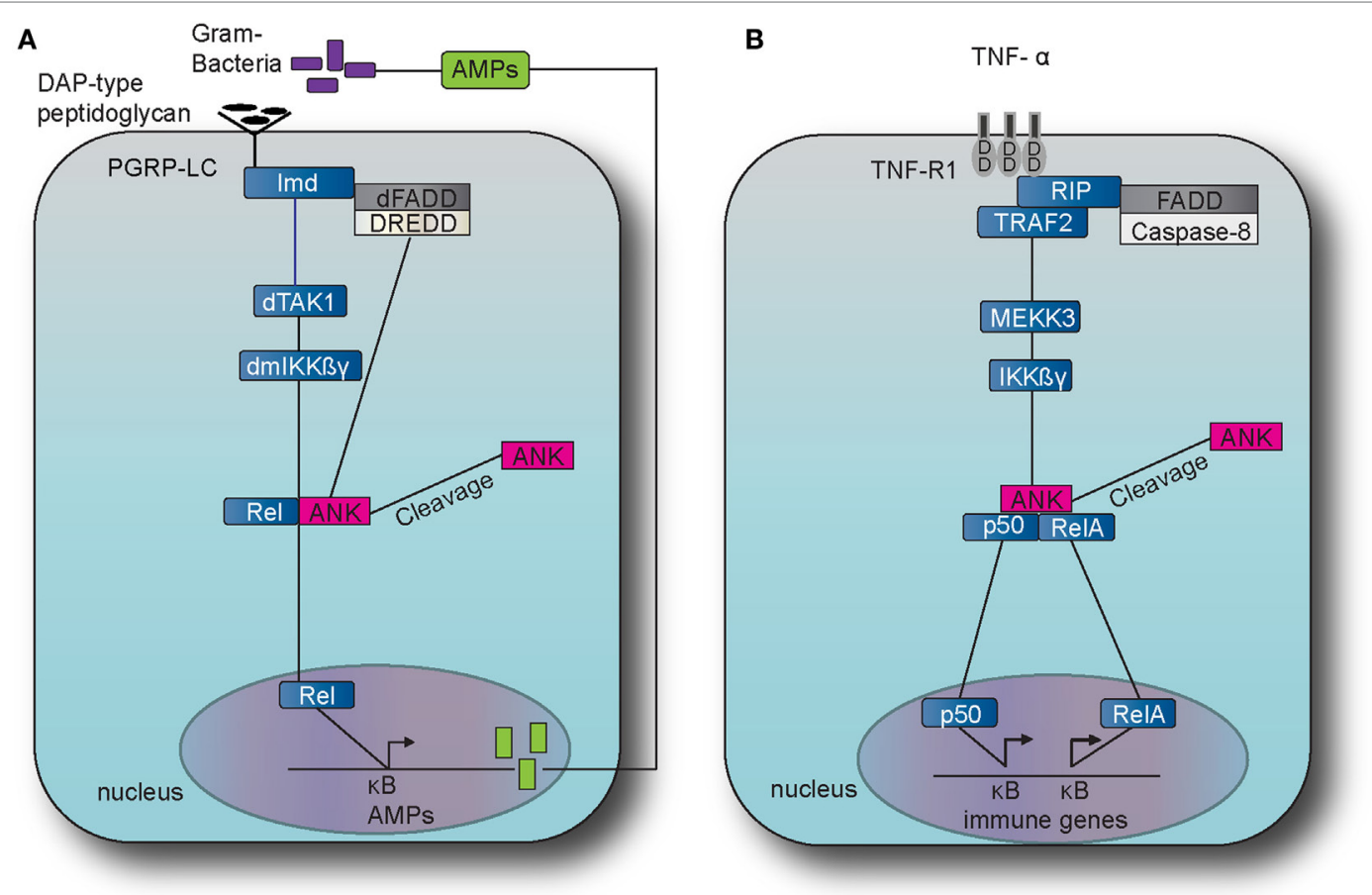

FIGURE 2 | The immune deficiency (IMD) pathway in fruit fly and the TNF pathway in the mouse. (A) The IMD pathway in Drosophila melanogaster is activated by Gram-negative bacteria and certain Gram-positive bacilli. The intracellular adaptor protein immune deficiency (Imd) interacts with the Drosophila Fas-associated death domain (dFADD) and the death-related ced-3/Nedd2-like caspase (DREDD) that cleaves Imd, which is then activated by K63 ubiquitination. This leads to the activation of the transforming growth factor beta activated kinase 1 (TAK1) that in turn activates the $D$. melanogaster inhibitor of kinase kinase $B$ and $\gamma$ complex (dmIKKBy). Activation results in the translocation of the nuclear factor-kappa B (NF-kB) transcription factor Relish (Rel) Dorsal to the nucleus which induces the transcription of antimicrobial peptide (AMP) genes, such as Diptericin. (B) The tumor necrosis factor (TNF) pathway in M. musculus is activated by TNF alpha (TNF- $\alpha$ ) which binds and activates the transmembrane receptors R1 (TNFR1) and recruits the receptor-interacting protein (RIP) and TNF receptor-associated factor 2 (TRAF2). TRAF2 employs mitogen-activated protein kinase kinase kinase 3 (MEKK3) which in turn activates the inhibitor of kinase kinase $B$ and $\gamma$ complex (IKKB $\gamma$ ), which results to the translocation of NF-KB transcription factors p50 and Rel A. The latter translocation induces expression of several genes that are involved to immunity and inflammation.

feedback loop in microglial cells causing perpetual inflammation and multiple brain responses including epigenetic suppression of GnRH genes in the hypothalamus (14). Microglial-derived NF- $\kappa \mathrm{B}-\mathrm{TNF}-\alpha$ axis plays a key role in homeostatic synaptic scaling, a form of synaptic plasticity. However, overexpression results in disrupted neuronal networks and behavior mimicking obsessive-compulsive disorder (OCD) $(43,44)$. Suppressing this pathway mediates some of the OCD-like behavioral problems in mouse models of frontotemporal dementia (44). Specifically, under-expression of NF- $\kappa \mathrm{B}$ in the mouse brain results in delayed onset of age-related pathology across all organ systems via preservation of the hypothalamic-pituitary-adrenal axis and $\mathrm{GnRH}$ levels (14).

\section{ENVIRONMENT}

\section{Neuronal Cell Lines/Human Autopsy Studies}

Type 2 diabetes mellitus (T2DM), a metabolic condition characterized by a decrease in sensitivity to endogenous insulin, is the best established environmental risk factor for the development of $\mathrm{AD}$, increasing relative risk by $50 \%$ (45). Diabetes induces $\mathrm{A} \beta$ pathology via NF- $\kappa \mathrm{B}$ upregulation and independent overexpression of BACE1 $(46,47)$. Inflammatory mediators are known to contribute to insulin resistance creating a pro-inflammatory feedback loop in diabetes (48). Administering advanced glycation end products that mimic diabetic driven pathology results in elevated BACE1 and consequent NF- $\mathrm{KB}$ overexpression in both rat brains in vivo and neuroblastoma cells lines (49). NF-кB suppression using Adiponectin rescues $A \beta$ pathology in human T2DM neuroblastoma cells (50). Similarly, leukotriene D4, an inflammatory signaling molecule elevated in metabolic disorders, induces $A \beta$ synthesis in primary neurons at $24 \mathrm{~h}$ with increases in $\mathrm{NF}-\kappa \mathrm{B}$ seen after just $1 \mathrm{~h}(51,52)$. Treatment of the culture with NF- $\kappa B$ inhibitor pyrrolidine dithiocarbamate (PDTC) inhibited $\mathrm{A} \beta$ generation with down regulation of $\mathrm{A} \beta$ generating beta- and gamma-secretase activity suggesting NF- $\kappa B$ regulates $A \beta$ synthesis in metabolic disease (52).

In human neuroblastoma cells, the metabolic enzyme protein arginine methyltransferase 5 (PRMT5) regulates cellular metabolism, protecting the cell in times of stress. $A \beta$ downregulates this process leading to NF- $\kappa \mathrm{B}$ overexpression, metabolic dysfunction, and premature cell death (53). Inhibiting NF- $\kappa B$ reduces 
apoptosis and $\mathrm{A} \beta$ deposits even in a metabolically dysfunctional organism or human cell lines suggesting a gatekeeper role for $\mathrm{NF}-\kappa \mathrm{B}$ in maintaining metabolic homeostasis and subsequent neuroprotection independent of PRMT5 activity (53).

\section{Invertebrate Models}

In Drosophila models of chronic diseases including $\mathrm{AD}$, the innate immune system has been identified as a key mediator of neurodegeneration $(13,34,54,55)$. NF- $\kappa \mathrm{B}$ overexpression in the fat body cells, analogous to the metabolic syndrome in humans, results in more severe neurodegeneration (56).

Supporting the role of NF- $\mathrm{BB}$ in connecting whole-body metabolism with brain health, NF- $\mathrm{KB}$ overexpression in the hypothalamus-like pars intercerebralis neurons in Drosophila results in overnutrition, impaired metabolic learning, poor memory consolidation, and metabolic disorder characterized by increased lipid levels and shortened lifespan (57). Conversely, genetic knockdown of NF-кB signaling in glial cells leads to elevated adipokinetic and glucagon-like hormone levels, reduced glucose and lipid levels, and extension of "healthspan" (13).

\section{Vertebrate Models}

In rodent and primate models, diabetes and obesity drive overexpression of NF- $\mathrm{\kappa B}$ in the hypothalamus creating a destructive feedback loop where further NF- $\kappa \mathrm{B}$ expression promotes hypertension, overnutrition, and decreased insulin sensitivity (58-61). Injecting $A \beta$ into the brains of mice and macaques results in an increase in NF- $\kappa \mathrm{B}$ in the cell nuclei of the hypothalamus and subsequent induction of peripheral glucose intolerance (62). In this model, pharmacological inhibition of NF- $\mathrm{\kappa B}$ maintained peripheral metabolic homeostasis. Inducing diabetes in rats results in hippocampal NF- $\kappa \mathrm{B}$-dependent neurodegeneration via disruption of CREB phosphorylation, reducing levels of protective downstream proteins including BDNF (63).

The tetracycline derivative Minocycline inhibits NF- $\mathrm{KB}$ and prevents further $A \beta$ deposition in a mouse model of diabetesdriven $\mathrm{AD}$. BACE1 activity remained elevated demonstrating an NF- $\kappa \mathrm{B}$-dependent protective mechanism (29). Mice fed on high-fat diets demonstrate elevated brain BACE1 expression as do transgenic diabetic mice. Administration of the anti-inflammatory agent all-trans-retinoic acid reduces BACE1 expression in both WT and mutant but this effect is abolished when the NF- $\mathrm{BB}-$ binding site at the promoter region of BACE1 is mutated (64).

\section{EMERGING RISK FACTORS}

\section{Alcohol Intake}

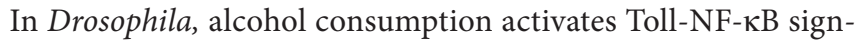
aling increasing ethanol resistance and gene products known to be outputs of innate immune signaling are rapidly induced following ethanol exposure (65). Ethanol treatment of cultured hippocampal rat neurons causes a dose- and time-dependent increase in NF- $\mathrm{KB}-\mathrm{DNA}$-binding activity, resulting in significant upregulation of inflammatory markers and increased susceptibility to neurotoxins; reversible by applying NF- $\mathrm{BB}$ inhibitors $(66,67)$.
Opposing, the consumption of moderate amounts of alcohol, particularly red wine, is associated with a reduced risk of AD. Anthocyanin, a polyphenol found in wines, protects rat hippocampal neurons against oxidative stress via NF- $\kappa \mathrm{B}$ suppression $(41,68)$.

\section{Sleep}

Sleep quality and well-being are symbiotic and reduced sleep quality is increasingly being associated with increased risk of dementia. Sleep-wake cycle homeostasis is important in the processing and removal of $A \beta$ plaques which, in turn, are known to dysregulate this reparative process (69). Sleep disruption and deprivation are known to cause over expression of the NF- $\kappa$ B pathway in hippocampal cell cultures, fruit flies, rodents, and humans (70-73). Improvement in sleep quality in older adults is

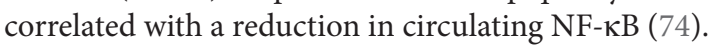

\section{Traumatic Brain Injury (TBI)}

Traumatic brain injury activates both microglia and astrocytes and induces self-sustaining inflammatory responses in the brain via NF- $\kappa \mathrm{B}$ activation $(75,76)$. In Drosophila, flies with TBI exhibited temporary incapacitation, ataxia, activation of the innate immune response, neurodegeneration, and death similar to humans with TBI $(77,78)$. Rat models have demonstrated the acute onset and prolonged overexpression of $\mathrm{NF}-\kappa \mathrm{B}$ in brain regions most commonly associated with post-injury atrophy (79, $80)$. Recent studies have shown NF- $\kappa \mathrm{B}$ to be significantly elevated in the ipsi-lateral cortex of both adult and old TBI mice in a timedependent manner (81). These interactions started immediately post-injury in the old mice compared to the adult mice suggesting an age-related failure of NF- $\mathrm{KB}$ suppression.

\section{PROTECTIVE FACTORS}

\section{Exercise}

Under expressing NF- $\kappa \mathrm{B}$ in mice results in greater endurance, cognitive performance, and resistance to obesity (82). An aerobic exercise protocol in wild-type rats attenuated age-related memory decline and decreased hippocampal NF- $\kappa \mathrm{B}$ levels and atrophy (83). In rats fed a pro-inflammatory diet and subjected to either strength training, aerobic exercise or a combination of both, all protocols reduced liver and muscle NF- $\kappa \mathrm{B}$ levels to pre-diet levels (84). These findings are supported by studies demonstrating the indirect suppression of NF- $\kappa \mathrm{B}$ via cytokine IL-10, a potent NF- $\kappa \mathrm{B}$ inhibitor, induced by exercise (85).

\section{Diet}

Curcumin, a constituent of turmeric, has gained much attention in recent years for its potential as a neuroprotective compound. In a Drosophila model of neurodegeneration, the curcumin analog C150 significantly reduced neuronal cell death, increased healthy lifespan, and reduced DNA mutation in brain tissue by suppress-

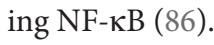

The neuroprotective effects resulting from the Mediterranean diet or those rich in oily fish may be mediated via the anti-inflammatory properties of key nutrients (87). A $\beta$ induced increases in the translocation NF- $\kappa \mathrm{B}$ subunits is attenuated in the presence of 
tyrosol (Tyr) and hydroxytyrosol (OH-Tyr) found abundantly in olive oil (88). Transgenic increases in omega-3 polyunsaturated fatty acid in the brain of mice reduces the inflammatory response to LPS challenge via NF- $\kappa$ B pathways (89).

The omega 3 fatty acid eicosapentaenoic acid indirectly downregulates NF- $\kappa \mathrm{B}$ expression acting as a ligand at peroxisome proliferator-activated receptor gamma, a regulator of fatty acid storage and glucose metabolism, and reduces symptoms of depression $(87,90)$. In $\mathrm{AD}$-mouse hippocampal slices, food-derived anti-oxidants provide neuroprotection and reduce $\mathrm{A} \beta$ via the antiinflammatory properties of the polyphenolic compounds within them (91). Specifically, the phenolic compound resveratrol reduces $\mathrm{A} \beta$-induced migroglial activity and neuroinflammation via NF- $\mathrm{BB}$ suppression in murine microglial and macrophage cells (92).

\section{Anti-inflammatory Drugs}

The prolonged use of non-steroidal anti-inflammatory drugs (NSAIDs) is associated with a reduction in the AD risk (93). In primary rat, neurons and human neuronal cell lines NSAIDs strongly inhibit NF- $\mathrm{KB}$-driven expression of BACE1 activity preventing the cleavage of A $\beta$ from $\operatorname{APP}(28,94)$. Long-term administration of potent NSAID indomethacin blocks activation of NF- $\kappa \mathrm{B}$ and significantly reduced the amyloid pathology in transgenic AD mice (95).

Aspirin, an NSAID derived from salicylic acid, completely inhibits $\mathrm{A} \beta$ activation of the NF- $\mathrm{BB}$ pathway, reducing levels of pro-inflammatory cytokines and chemokines, and increasing levels of anti-inflammatory IL-10 in rodent microglia and neurons resulting in recruitment of $\mathrm{A} \beta$ phagocytic microglia and improved cognitive and synaptic functioning $(28,96)$.

\section{REFERENCES}

1. Wimo A, Jönsson L, Bond J, Prince M, Winblad B, International AD. The worldwide economic impact of dementia 2010. Alzheimer Dement (2013) 9(1):1-11. doi:10.1016/j.jalz.2012.11.006

2. Wimo A, Guerchet M, Ali G-C, Wu Y-T, Prina AM, Winblad B, et al. The worldwide costs of dementia 2015 and comparisons with 2010. Alzheimers Dement (2017) 13(1):1-7. doi:10.1016/j.jalz.2016.07.150

3. Jack CR, Knopman DS, Jagust WJ, Shaw LM, Aisen PS, Weiner MW, et al. Hypothetical model of dynamic biomarkers of the Alzheimer's pathological cascade. Lancet Neurol (2010) 9(1):119-28. doi:10.1016/S1474-4422(09)70299-6

4. Imtiaz B, Tolppanen AM, Kivipelto M, Soininen H. Future directions in Alzheimer's disease from risk factors to prevention. Biochem Pharmacol (2014) 88(4):661-70. doi:10.1016/j.bcp.2014.01.003

5. Gauthier S, Albert M, Fox N, Goedert M, Kivipelto M, MestreFerrandiz J, et al. Why has therapy development for dementia failed in the last two decades? Alzheimer Dement (2016) 12(1):60-4. doi:10.1016/j.jalz. 2015.12.003

6. Hawkes N. Promise of new Alzheimer's drug is dashed after lack of evidence. BMJ (2016) 355:i6362. doi:10.1136/bmj.i6362

7. Vijaya Kumar DK, Choi SH, Washicosky KJ, Eimer WA, Tucker S, Ghofrani J, et al. Amyloid- $\beta$ peptide protects against microbial infection in mouse and worm models of Alzheimer's disease. Sci Transl Med (2016) 8(340):340ra72. doi:10.1126/scitranslmed.aaf1059

8. Robinson M, Brenda Y, Lee A, Francis T, Hane J. Recent progress in Alzheimer's disease research, part 2: genetics and epidemiology. Alzheimer Dement (2017) 57(2):317-30. doi:10.3233/JAD-161149

9. Zhao Y, Bhattacharjee S, Jones BM, Dua P, Alexandrov PN, Hill JM, et al. Regulation of TREM2 expression by an NF- $\kappa B$-sensitive miRNA-34a. Neuroreport (2013) 24(6):318-23. doi:10.1097/WNR.0b013e32835fb6b0

\section{CONCLUSION}

Epidemiological studies are beginning to converge of common risk factors for the development of $\mathrm{AD}$ with strong signals also emerging for certain protective factors. The emergence of NF- $\mathrm{KB}$ as a regulator of aging and proliferation of studies implicating NF- $\mathrm{kB}$ over-activation in a number of neurodegenerative diseases suggests that it may be important in modulating the risk of disease. This review has highlighted the intimate relationship between all known and emerging risk and protective factors for Alzheimer's and NF- $\mathrm{\kappa B}$ activity, implicating over-activation with an increased risk of the disease and suppression being associated with risk reduction. Future work, both in models of disease and trials in man, should focus on therapies that directly target NF- $\mathrm{\kappa B}$ overexpression to explore whether early risk identification and targeted anti-inflammatory treatment can significantly increase the time of disease onset and, consequently, reduce the incidence of this devastating disease.

\section{AUTHOR CONTRIBUTIONS}

SJ and IK wrote the manuscript, and IK designed the figures.

\section{FUNDING}

This work was supported by Consolidator Grant 310912 (Drosoparasite) from the European Research Council to Prof. Petros Ligoxygakis and by funding from the National Institute for Social Care and Health Research.

10. Griciuc A, Serrano-Pozo A, Parrado AR, Lesinski AN, Asselin CN, Mullin K et al. Alzheimer's disease risk gene CD33 inhibits microglial uptake of amyloid beta. Neuron (2013) 78(4):631-43. doi:10.1016/j.neuron.2013.04.014

11. Zhu XC, Yu JT, Jiang T, Wang P, Cao L, Tan L. CR1 in Alzheimer's disease. Mol Neurobiol (2015) 51(2):753-65. doi:10.1007/s12035-014-8723-8

12. Li X, Long J, He T, Belshaw R, Scott J. Integrated genomic approaches identify major pathways and upstream regulators in late onset Alzheimer's disease. Sci Rep (2015) 5:12393. doi:10.1038/srep12393

13. Kounatidis I, Chtarbanova S, Cao Y, Hayne M, Jayanth D, Ganetzky B, et al. $\mathrm{NF}-\kappa \mathrm{B}$ immunity in the brain determines fly lifespan in healthy aging and age-related neurodegeneration. Cell Rep (2017) 19(4):836-48. doi:10.1016/j. celrep.2017.04.007

14. Sadagurski M, Cady G, Miller RA. Anti-aging drugs reduce hypothalamic inflammation in a sex-specific manner. Aging Cell (2017) 16(4):652-6602017. doi:10.1111/acel.12590

15. Kaltschmidt B, Sparna T, Kaltschmidt C. Activation of NF- $\kappa B$ by reactive oxygen intermediates in the nervous system. Antioxid Redox Signal (1999) 1(2):129-44. doi:10.1089/ars.1999.1.2-129

16. Kounatidis I, Ligoxygakis P. Drosophila as a model system to unravel the layers of innate immunity to infection. Open Biol (2012) 2(5):120075. doi:10.1098/ rsob. 120075

17. Wang L, Kounatidis I, Ligoxygakis P. Drosophila as a model to study the role of blood cells in inflammation, innate immunity and cancer. Front Cell Infect Microbiol (2014) 3:113. doi:10.3389/fcimb.2013.00113

18. Meffert MK, Chang JM, Wiltgen BJ, Fanselow MS, Baltimore D. NF- $\kappa B$ functions in synaptic signalling and behaviour. Nat Neurosci (2003) 6(10):1072-8. doi:10.1038/nn1110

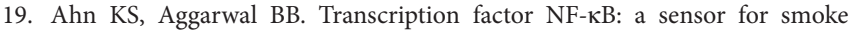
and stress signals. Ann N Y Acad Sci (2005) 1056(1):218-33. doi:10.1196/ annals. 1352.026 
20. Karunaweera N, Raju R, Gyengesi E, Münch G. Plant polyphenols as inhibitors of NF- $\kappa \mathrm{B}$ induced cytokine production - a potential anti-inflammatory treatment for Alzheimer's disease? Front Mol Neurosci (2015) 8:24. doi:10.3389/ fnmol.2015.00024

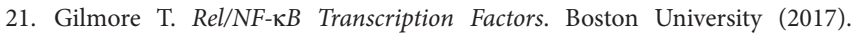
Available from: www.nf-kb.org. 2017

22. Feng Y, Li X, Zhou W, Lou D, Huang D, Li Y, et al. Regulation of set gene expression by nfkb. Mol Neurobiol (2016) 54(6):4477-85. doi:10.1007/ s12035-016-9967-2

23. Kawahara TL, Michishita E, Adler AS, Damian M, Berber E, Lin M, et al. SIRT6 links histone $\mathrm{H} 3$ lysine 9 deacetylation to NF- $\mathrm{KB}$-dependent gene expression and organismal life span. Cell (2009) 136(1):62-74. doi:10.1016/j. cell.2008.10.052

24. Natoli G. When sirtuins and NF-кB collide. Cell (2009) 136(1):19-21. doi:10.1016/j.cell.2008.12.034

25. Reitz C, Brayne C, Mayeux R. Epidemiology of Alzheimer disease. Nat Rev Neurol (2011) 7(3):137-52. doi:10.1038/nrneurol.2011.2

26. Sindi S, Mangialasche F, Kivipelto $M$. Advances in the prevention of Alzheimer's disease. F1000Prime Rep (2015) 7:50. doi:10.12703/P7-50

27. Grilli M, Ribola M, Alberici A, Valerio A, Memo M, Spano P. Amyloid precursor protein (APP) gene expression is controlled by a NFkB/Rel related protein. In: Hanin I, Yoshida M, Fisher A, editors. Alzheimer's and Parkinson's Diseases Part of the Advances in Behavioral Biology Book Series ABBI. (Vol. 44). US: Springer (1995). p. 105-10.

28. Chen CH, Zhou W, Liu S, Deng Y, Cai F, Tone M, et al. Increased NF- $\kappa$ B signalling up-regulates BACE1 expression and its therapeutic potential in Alzheimer's disease. Int J Neuropsychopharmacol (2012) 15(1):77-90. doi:10.1017/ S1461145711000149

29. Cai Z, Zhao Y, Yao S, Zhao B. Increases in $\beta$-amyloid protein in the hippocampus caused by diabetic metabolic disorder are blocked by minocycline through inhibition of NF-кB pathway activation. Pharmacol Rep (2011) 63(2):381-91. doi:10.1016/S1734-1140(11)70504-7

30. Liu C-C, Kanekiyo T, Xu H, Bu G. Apolipoprotein E and Alzheimer disease: risk, mechanisms, and therapy. Nat Rev Neurol (2013) 9(2):106-18. doi:10.1038/nrneurol.2012.263

31. Zhang KJ, Zhang HL, Zhang XM, Zheng XY, Quezada HC, Zhang D, et al. Apolipoprotein $\mathrm{E}$ isoform-specific effects on cytokine and nitric oxide production from mouse Schwann cells after inflammatory stimulation. Neurosci Lett (2011) 499(3):175-80. doi:10.1016/j.neulet.2011.05.050

32. Theendakara VP, Peters-Libeu C, Bredesen DE, Rao RV. Novel transcriptional role of Apo e4. Alzheimers Dement (2016) 12(7):224. doi:10.1016/j. jalz.2016.06.400

33. Conejero-Goldberg C, Hyde TM, Chen S, Herman MM, Kleinman JE, Davies P, et al. Cortical transcriptional profiles in APOE4 carriers with Alzheimer's disease: patterns of protection and degeneration. J Alzheimer Dis (2015) 48(4):969-78. doi:10.3233/JAD-150345

34. Tan L, Schedl P, Song H-J, Garza D, Konsolaki M. The Toll $\rightarrow$ NF- $\kappa B$ signaling pathway mediates the neuropathological effects of the human Alzheimer's A 342 polypeptide in Drosophila. PLoS One (2008) 3(12):e3966. doi:10.1371/ journal.pone.0003966

35. Sarantseva S, Timoshenko S, Bolshakova O, Karaseva E, Rodin D, Schwarzman AL, et al. Apolipoprotein E-mimetics inhibit neurodegeneration and restore cognitive functions in a transgenic Drosophila model of Alzheimer's disease. PLoS One (2009) 4(12):e8191. doi:10.1371/journal. pone.0008191

36. Franceschi C, Capri M, Monti D, Giunta S, Olivieri F, Sevini F, et al. Inflammaging and anti-inflammaging: a systemic perspective on aging and longevity emerged from studies in humans. Mech Ageing Dev (2007) 128(1):92-105. doi:10.1016/j.mad.2006.11.016

37. Holtman IR, Raj DD, Miller JA, Schaafsma W, Yin Z, Brouwer N, et al. Induction of a common microglia gene expression signature by aging and neurodegenerative conditions: a co-expression meta-analysis. Acta Neuropathol Commun (2015) 3:31. doi:10.1186/s40478-015-0203-5

38. Kim MK, Chung SW, Kim DH, Kim JM, Lee EK, Kim JY, et al. Modulation of age-related NF- $\kappa \mathrm{B}$ activation by dietary zingerone via MAPK pathway. Exp Gerontol (2010) 45(6):419-26. doi:10.1016/j.exger.2010.03.005

39. Jeong JJ, Woo JY, Kim KA, Han MJ, Kim DH. Lactobacillus pentosus var. plantarum C29 ameliorates age-dependent memory impairment in
Fischer 344 rats. Lett Appl Microbiol (2015) 60(4):307-14. doi:10.1111/ lam. 12393

40. Niu Y-L, Zhang W-J, Wu P, Liu B, Sun G-T, Yu D-M, et al. Expression of the apoptosis-related proteins caspase- 3 and NF- $\kappa$ B in the hippocampus of Tg2576 mice. Neurosci Bull (2010) 26(1):37-46. doi:10.1007/s12264-010-6122-3

41. Rehman SU, Shah SA, Ali T, Chung JI, Kim MO. Anthocyanins reversed D-galactose-induced oxidative stress and neuroinflammation mediated cognitive impairment in adult rats. Mol Neurobiol (2017) 54(1):255-71. doi:10.1007/s12035-015-9604-5

42. Jurk D, Wilson C, Passos JF, Oakley F, Correia-Melo C, Greaves L, et al. Chronic inflammation induces telomere dysfunction and accelerates ageing in mice. Nat Commun (2014) 2:4172. doi:10.1038/ncomms5172

43. Stellwagen D, Malenka RC. Synaptic scaling mediated by glial TNF-alpha. Nature (2006) 440(7087):1054-9. doi:10.1038/nature04671

44. Krabbe G, Minami SS, Etchegaray JI, Taneja P, Djukic B, Davalos D, et al. Microglial NFkB-TNF $\alpha$ hyperactivation induces obsessive-compulsive behavior in mouse models of progranulin-deficient frontotemporal dementia. Proc Natl Acad Sci U S A (2017) 114(19):5029-34. doi:10.1073/pnas. 1700477114

45. Li X, Song D, Leng SX. Link between type 2 diabetes and Alzheimer's disease: from epidemiology to mechanism and treatment. Clin Interv Aging (2015) 10:549. doi:10.2147/CIA.S74042

46. Vassar R, Kuhn P-H, Haass C, Kennedy ME, Rajendran L, Wong PC, et al. Function, therapeutic potential and cell biology of BACE proteases: current status and future prospects. J Neurochem (2014) 130(1):4-28. doi:10.1111/ jnc. 12715

47. Jonsson T, Atwal JK, Steinberg S, Snaedal J, Jonsson PV, Bjornsson S, et al. A mutation in APP protects against Alzheimer's disease and age-related cognitive decline. Nature (2012) 488(7409):96-9. doi:10.1038/nature11283

48. Shoelson SE, Lee J, Goldfine AB. Inflammation and insulin resistance. J Clin Invest (2006) 116(7):1793-801. doi:10.1172/JCI29069

49. Guglielmotto M, Aragno M, Tamagno E, Vercellinatto I, Visentin S, Medana C, et al. AGEs/RAGE complex upregulates BACE1 via NF-кB pathway activation. Neurobiol Aging (2012) 33(1):.e13-27. doi:10.1016/j. neurobiolaging.2010.05.026

50. Chan K-H, Lam KS-L, Cheng O-Y, Kwan JS-C, Ho PW-L, Cheng KK-Y, et al. Adiponectin is protective against oxidative stress induced cytotoxicity in amyloid-beta neurotoxicity. PLoS One (2012) 7(12):e52354. doi:10.1371/ journal.pone.0052354

51. Long EK, Hellberg K, Foncea R, Hertzel AV, Suttles J, Bernlohr DA. Fatty acids induce leukotriene $\mathrm{C}_{4}$ synthesis in macrophages in a fatty acid binding protein-dependent manner. Biochim Biophys Acta (2013) 1831(7):1199-207. doi:10.1016/j.bbalip.2013.04.004

52. Wang XY, Tang SS, Hu M, Long Y, Li YQ, Liao MX, et al. Leukotriene D4 induces amyloid- $\beta$ generation via CysLT 1 R-mediated NF- $\kappa \mathrm{B}$ pathways in primary neurons. Neurochem Int (2013) 62(3):340-7. doi:10.1016/j. neuint.2013.01.002

53. Quan X, Yue W, Luo Y, Cao J, Wang H, Wang Y, et al. The protein arginine methyltransferase PRMT5 regulates A $\beta$-induced toxicity in human cells and Caenorhabditis elegans models of Alzheimer's disease. J Neurochem (2015) 134(5):969-77. doi:10.1111/jnc.13191

54. Petersen AJ, Wassarman DA. Drosophila innate immune response pathways moonlight in neurodegeneration. Fly (2012) 6(3):169-72. doi:10.4161/ fly.20999

55. Lim Y-M, Tsuda L. Ebi, a Drosophila homologue of TBL1, regulates the balance between cellular defense responses and neuronal survival. Am J Neurodegener Dis (2016) 5(1):62-8.

56. Lim Y-M, Yagi Y, Tsuda L. Cellular defense and sensory cell survival require distinct functions of ebi in Drosophila. PLoS One (2015) 10(11):e0141457. doi:10.1371/journal.pone.0141457

57. Zhang Y, Liu G, Yan J, Zhang Y, Li B, Cai D. Metabolic learning and memory formation by the brain influence systemic metabolic homeostasis. Nat Commun (2015) 6:6704. doi:10.1038/ncomms7704

58. Zhang X, Zhang G, Zhang H, Karin M, Bai H, Cai D. Hypothalamic IKK $\beta$ / NF- $\kappa \mathrm{B}$ and ER stress link overnutrition to energy imbalance and obesity. Cell (2008) 135(1):61-73. doi:10.1016/j.cell.2008.07.043

59. Posey KA, Clegg DJ, Printz RL, Byun J, Morton GJ, Vivekanandan-Giri A, et al. Hypothalamic proinflammatory lipid accumulation, inflammation, and 
insulin resistance in rats fed a high-fat diet. Am J Physiol Endocrinol Metab (2009) 296(5):E1003-12. doi:10.1152/ajpendo.90377.2008

60. Baker RG, Hayden MS, Ghosh S. NF-kB, inflammation, and metabolic disease. Cell Metab (2011) 13(1):11-22. doi:10.1016/j.cmet.2010.12.008

61. Purkayastha S, Zhang G, Cai D. Uncoupling the mechanisms of obesity and hypertension by targeting hypothalamic IKK-[beta] and NF-[kappa] B. Nat Med (2011) 17(7):883-7. doi:10.1038/nm.2372

62. Clarke JR, e Silva NML, Figueiredo CP, Frozza RL, Ledo JH, Beckman D, et al. Alzheimer-associated $A \beta$ oligomers impact the central nervous system to induce peripheral metabolic deregulation. EMBO Mol Med (2015) 7(2):190-210. doi:10.15252/emmm.201404183

63. Qin LM, Bouchard R, Pugazhenthi S. Regulation of cyclic AMP response element-binding protein during neuroglial interactions. J Neurochem (2016) 136(5):918-30. doi:10.1111/jnc.13497

64. Wang R, Chen S, Liu Y, Diao S, Xue Y, You X, et al. All-trans-retinoic acid reduces BACE1 expression under inflammatory conditions via modulation of nuclear factor $\mathrm{\kappa B}$ (NFKB) signaling. J Biol Chem (2015) 290(37):22532-42. doi:10.1074/jbc.M115.662908

65. Troutwine BR, Ghezzi A, Pietrzykowski AZ, Atkinson NS. Alcohol resistance in Drosophila is modulated by the Toll innate immune pathway. Genes Brain Behav (2016) 15(4):382-94. doi:10.1111/gbb.12288

66. Zou J, Crews F. CREB and NF-kappaB transcription factors regulate sensitivity to excitotoxic and oxidative stress induced neuronal cell death. Cell Mol Neurobiol (2006) 26:385-405. doi:10.1007/s10571-006-9045-9

67. ZouJ,CrewsF.Inductionofinnateimmunegeneexpressioncascadesinbrainslice cultures by ethanol: key role of NF- $\mathrm{\kappa B}$ and proinflammatory cytokines. Alcohol Clin Exp Res (2010) 34(5):777-89. doi:10.1111/j.1530-0277.2010.01150.x

68. Shah SA, Yoon GH, Kim MO. Protection of the developing brain with anthocyanins against ethanol-induced oxidative stress and neurodegeneration. Mol Neurobiol (2015) 51(3):1278-91. doi:10.1007/s12035-014-8805-7

69. Mander BA, Marks SM, Vogel JW, Rao V, Lu B, Saletin JM, et al. $\beta$-amyloid disrupts human NREM slow waves and related hippocampus-dependent memory consolidation. Nat Neurosci (2015) 18(7):1051-7. doi:10.1038/ nn. 4035

70. Narasimamurthy R, Hatori M, Nayak SK, Liu F, Panda S, Verma IM. Circadian clock protein cryptochrome regulates the expression of proinflammatory cytokines. Proc Natl Acad Sci U S A (2012) 109(31):12662-7. doi:10.1073/ pnas.1209965109

71. Williams JA, Sathyanarayanan S, Hendricks JC, Sehgal A. Interaction between sleep and the immune response in Drosophila: a role for the NF-кB Relish. Sleep (2007) 30(4):389-400. doi:10.1093/sleep/30.4.389

72. Israel LP, Benharoch D, Gopas J, Goldbart AD. A pro-inflammatory role for nuclear factor kappa B in childhood obstructive sleep apnea syndrome. Sleep (2013) 36(12):1947. doi:10.5665/sleep.3236

73. Angelo MF, Aguirre A, Reyes RXA, Villarreal A, Lukin J, Melendez M, et al. The proinflammatory RAGE/NF- $\mathrm{\kappa B}$ pathway is involved in neuronal damage and reactive gliosis in a model of sleep apnea by intermittent hypoxia. PLoS One (2014) 9(9):e107901. doi:10.1371/journal.pone.0107901

74. Black DS, O'Reilly GA, Olmstead R, Breen EC, Irwin MR. Mindfulness meditation and improvement in sleep quality and daytime impairment among older adults with sleep disturbances: a randomized clinical trial. JAMA Intern Med (2015) 175(4):494-501. doi:10.1001/jamainternmed.2014. 8081

75. Van Den Heuvel C, Thornton E, Vink R. Traumatic brain injury and Alzheimer's disease: a review. Prog Brain Res (2007) 161:303-16. doi:10.1016/ S0079-6123(06)61021-2

76. Jayakumar AR, Tong XY, Ruiz-Cordero R, Bregy A, Bethea JR, Bramlett HM, et al. Activation of NF- $\mathrm{\kappa B}$ mediates astrocyte swelling and brain edema in traumatic brain injury. J Neurotrauma (2014) 31(14):1249-57. doi:10.1089/ neu.2013.3169

77. Katzenberger RJ, Chtarbanova S, Rimkus SA, Fischer JA, Kaur G, Seppala JM, et al. Death following traumatic brain injury in Drosophila is associated with intestinal barrier dysfunction. Elife (2015) 4:e04790. doi:10.7554/ eLife.04790

78. Barekat A, Gonzalez A, Mauntz RE, Kotzebue RW, Molina B, ElMecharrafie N, et al. Using Drosophila as an integrated model to study mild repetitive traumatic brain injury. Sci Rep (2016) 6:25252. doi:10.1038/ srep25252
79. Nonaka M, Chen XH, Pierce JE, Leoni MJ, Mcintosh TK, Wolf JA, et al. Prolonged activation of NF- $\mathrm{\kappa B}$ following traumatic brain injury in rats. J Neurotrauma (1999) 16(11):1023-34. doi:10.1089/neu.1999.16.1023

80. Lipponen A, Paananen J, Puhakka N, Pitkänen A. Analysis of post-traumatic brain injury gene expression signature reveals tubulins, Nfe2l2, Nfkb, Cd44, and S100a4 as treatment targets. Sci Rep (2016) 17(6):31570. doi:10.1038/ srep31570

81. Gupta RK, Prasad S. Age-dependent alterations in the interactions of NF-kB and N-myc with GLT-1/EAAT2 promoter in the pericontusional cortex of mice subjected to traumatic brain injury. Mol Neurobiol (2016) 53(5):3377-88. doi:10.1007/s12035-015-9287-y

82. Minegishi Y, Haramizu S, Misawa K, Shimotoyodome A, Hase T, Murase T. Deletion of nuclear factor- $\mathrm{\kappa B}$ p50 upregulates fatty acid utilization and contributes to an anti-obesity and high-endurance phenotype in mice. Am JPhysiol Endocrinol Metab (2015) 309(6):E523-33. doi:10.1152/ajpendo. 00071.2015

83. Lovatel GA, Elsner VR, Bertoldi K, Vanzella C, Moysés Fdos S, Vizuete A, et al. Treadmill exercise induces age-related changes in aversive memory, neuroinflammatory and epigenetic processes in the rat hippocampus. Neurobiol Learn $\operatorname{Mem}$ (2013) 101:94-102. doi:10.1016/j.nlm.2013.01.007

84. Botezelli JD, Coope A, Ghezzi AC, Cambri LT, Moura LP, Scariot PP, et al. Strength training prevents hyperinsulinemia, insulin resistance, and inflammation independent of weight loss in fructose-fed animals. Sci Rep (2016) 6:31106. doi:10.1038/srep31106

85. Ropelle ER, Flores MB, Cintra DE, Rocha GZ, Pauli JR, Morari J, et al. IL-6 and IL-10 anti-inflammatory activity links exercise to hypothalamic insulin and leptin sensitivity through IKK $\beta$ and ER stress inhibition. PLoS Biol (2010) 8(8):e1000465. doi:10.1371/journal.pbio.1000465

86. Hackler L Jr, Ózsvári B, Gyuris M, Sipos P, Fábián G, Molnár E, et al. The curcumin analog C-150, influencing NF- $\mathrm{kB}$, UPR and Akt/Notch pathways has potent anticancer activity in vitro and in vivo. PLoS One (2016) 11(3):e0149832. doi:10.1371/journal.pone.0149832

87. Hallahan B, Ryan T, Hibbeln JR, Murray IT, Glynn S, Ramsden CE, et al. Efficacy of omega-3 highly unsaturated fatty acids in the treatment of depression. Br J Psychiatry (2016) 209(3):192-201. doi:10.1192/bjp.bp.114. 160242

88. St-Laurent-Thibault C, Arseneault M, Longpre F, Ramassamy C. Tyrosol and hydroxytyrosol two main components of olive oil, protect N2a cells against amyloid- $\beta$-induced toxicity. involvement of the NF- $\mathrm{BB}$ signaling. Curr Alzheimer Res (2011) 8(5):543-51. doi:10.2174/156720511796391845

89. Godbout JP, Berg BM, Krzyszton C, Johnson RW. $\alpha$-Tocopherol attenuates $\mathrm{NF}-\mathrm{\kappa B}$ activation and pro-inflammatory cytokine production in brain and improves recovery from lipopolysaccharide-induced sickness behavior. J Neuroimmunol (2005) 169(1):97-105. doi:10.1016/j.jneuroim.2005.08.003

90. Gold PW, Licinio J, Pavlatou MG. Pathological parainflammation and endoplasmic reticulum stress in depression: potential translational targets through the CNS insulin, klotho and PPAR- $\gamma$ systems. Mol Psychiatry (2013) 18(2):154-65. doi:10.1038/mp.2012.167

91. Wang J, Bi W, Cheng A, Freire D, Vempati P, Zhao W, et al. Targeting multiple pathogenic mechanisms with polyphenols for the treatment of Alzheimer's disease-experimental approach and therapeutic implications. Front Aging Neurosci (2014) 14(6):42. doi:10.3389/fnagi.2014.00042

92. Capiralla H, Vingtdeux V, Zhao H, Sankowski R, Al-Abed Y, Davies P, et al. Resveratrol mitigates lipopolysaccharide- and A $\beta$-mediated microglial inflammation by inhibiting the TLR4/NF-KB/STAT signaling cascade. J Neurochem (2012) 120(3):461-72. doi:10.1111/j.1471-4159.2011.07594.x

93. Wentzell J, Kretzschmar D. Alzheimer's disease and tauopathy studies in flies and worms. Neurobiol Dis (2010) 40(1):21-8. doi:10.1016/j.nbd.2010.03.007

94. Valerio A, Boroni F, Benarese M, Sarnico I, Ghisi V, Bresciani LG, et al. NF-KB pathway: a target for preventing $\beta$-amyloid $(\mathrm{A} \beta)$-induced neuronal damage and A 342 production. Eur J Neurosci (2006) 23(7):1711-20. doi:10.1111/j.1460-9568.2006.04722.x

95. Sung S, Yang H, Uryu K, Lee EB, Zhao L, Shineman D, et al. Modulation of nuclear factor- $\mathrm{\kappa B}$ activity by indomethacin influences $\mathrm{A} \beta$ levels but not $\mathrm{A} \beta$ precursor protein metabolism in a model of Alzheimer's disease. Am J Pathol (2004) 165(6):2197-206. doi:10.1016/S0002-9440(10)63269-5

96. Medeiros R, Kitazawa M, Passos GF, Baglietto-Vargas D, Cheng D, Cribbs $\mathrm{DH}$, et al. Aspirin-triggered lipoxin A 4 stimulates alternative 
activation of microglia and reduces Alzheimer disease-like pathology in mice. Am J Pathol (2013) 182(5):1780-9. doi:10.1152/ajpendo.00071.2015

Conflict of Interest Statement: The authors declare that the research was conducted in the absence of any commercial or financial relationships that could be construed as a potential conflict of interest.
Copyright $\odot 2017$ Jones and Kounatidis. This is an open-access article distributed under the terms of the Creative Commons Attribution License (CC BY). The use, distribution or reproduction in other forums is permitted, provided the original author(s) or licensor are credited and that the original publication in this journal is cited, in accordance with accepted academic practice. No use, distribution or reproduction is permitted which does not comply with these terms. 